\title{
Spinal cord injuries - Epidemiology in Portugal's central region
}

\author{
Fernando Martins ${ }^{1}$, Filomena Freitas ${ }^{1}$, Lília Martins ${ }^{1}$, Jean François Dartigues ${ }^{2}$ and Michel Barat ${ }^{2}$ \\ ${ }^{1}$ Serviço de Medicina Fisica e Reabilitaçad Centro Hospitalar de Coimbra, Quinta de Vales, 3000 Coimbra, Portugal \\ and ${ }^{2}$ University of Bordeaux II, 156 R. Leo Saignat 33000 Bordeaux, France
}

\begin{abstract}
This study concerns spinal cord injuries (SCI) in a region of Portugal with a population of 1721650 inhabitants. Legislation has made it possible to identify deaths occurring during collection and transport. Between 1989 and 1992, 398 new cases of spinal cord injuries were identified, of which $77 \%$ were male and $23 \%$ female. The average age was 50 , with a range of between 1 and 92 . As far as the type of injury is concerned, there were 154 isolated SCI (38.7\%); in 120 cases $(30.1 \%)$ there were multiple associated injuries; in 66 cases $(16.6 \%)$ there was an associated traumatic brain injury; in 34 cases $(8.5 \%)$ there was an associated trauma of the thorax. In the hospitals concerned no Injury Severity Score (ISS) was carried out during hospitalization. Sixty-four (16\%) were dead upon arrival at hospital, and $159(40 \%)$ died before release. The average length of hospitalization was 26.6 days, with the maximum being 539 days. The annual incidence rate is 57.8 new cases per million inhabitants, including those who died before being admitted to hospital. The annual survival rate is 25.4 new cases per million inhabitants. The death rate is very high during the first week, peaking during the first $24 \mathrm{~h}$.
\end{abstract}

Keywords: spinal cord injury; incidence; mortality; rehabilitation

\section{Introduction}

It is very difficult to obtain reliable epidemiological data for a comparative study of one country or continent with another ${ }^{1-5}$ due to differences in social structure, therapeutic procedures and data-gathering systems.

Most published studies do not consider the whole therapeutic procedure of SCI, particularly the prehospital collection and transport phase. In some countries $^{6-9}$ autopsy is compulsory in all cases of traumatic death. This permits an exhaustive study of all cases occurring within a given period, including those which were not diagnosed prior to autopsy. Some authors ${ }^{10,11}$ consider cases of death in the acute phase on the basis of both death certificates and autopsy reports, or death certificate alone. In this case, the real scale of SCI is underestimated; ${ }^{5,7}$ however, it is closer to reality than those which systematically omit the pre-hospital phase. ${ }^{12-29}$

Within a framework of public health, prevention, and treatment, and from the perspective of regional or national economics, the real epidemiological scale of SCI will never be completely known if only the survivors of the acute phase are considered. Any procedure which aims to reduce the number and severity of SCI must take into account deaths in the pre-hospital phase.

\section{Methodology}

In the central region of Portugal local hospitals do not have neurosurgery departments, and treatment of this

Correspondence: F Martins, Rua Miguel Torga, 353, $4^{\circ}$ Esq., 3030 Coimbra, Portugal kind of injury cannot be guaranteed by the orthopedic departments. Therefore, all SCI are treated during the acute phase at the Coimbra hospitals: the Coimbra Hospital Center (CHC) and the Coimbra University Hospitals (HUC). Records in each of these centers were computerized, using ICD-9-CM codification system; we have reviewed all clinical files classified as SCI, with or without bone lesion (codes 806 and 952) occurring between 1989 and 1992 in patients hospitalized in the Coimbra hospitals.

In order for this study to be representative of all SCI occurring in the Central Region, it is necessary to identify victims who were not transported to these hospitals, either because they were admitted to local hospitals or because they died in the accident or during transportation.

In Portugal, any deaths resulting from violent impact or trauma are subjected to judicial autopsy, ${ }^{6}$ including deaths from traffic accidents. If death takes place in a public hospital, the body is taken to the department of legal medicine. In the case of deaths occurring outside a public hospital (on the road, for example), the body may not be removed until authorized by a medical expert from either the Institute of Legal Medicine (ILM) or the circuit court. The body is then taken to the department of Legal Medicine. ${ }^{6}$

As the epidemiological network in Portugal is relatively clear, it was possible to identify all SCI occurring between 1st January 1989 and 31st December 1992, and also the mortality rate in the intial phase, including deaths occurring on public 
highways or during transportation; this information was exhaustively researched by means of a complementary study of admissions to hospital and to the Coimbra Institute of Legal Medicine (ILM).

As family names are frequently very long in Portugal, and abbreviations may lead to error, we chose to use the complete names on our records, along with the date of accident and place of residence; this information is processed using 'File Maker Pro', which permits the identification of any eventual duplications.

\section{Definition of spinal cord injury}

Spinal cord injury is defined as an acute traumatic injury of the spinal cord, including cauda equina and conus medullaris injuries, but not lumbrosacral plexus lesions or injury to peripheral nerves outside the neural canal, ${ }^{30}$ causing motor or sensory deficiency to varying degrees, or neurogenic bladder or intestine. ${ }^{1}$ SCI resulting from degenerative osteo-articular alterations of the rachis, degenerative lesions of the Central Nervous System, congenital lesions and primary or secondary tumoral lesions were not included.

The diagnosis of SCI was taken from the clinical records of hospitalization or autopsy.

\section{Transversal extension of lesion}

The definition of complete or incomplete lesion was made on the basis of interpretation of existing data in clinical files, according to ASIA - IMSOP criteria. ${ }^{30}$

\section{Population at risk}

Portugal has an area of $92082 \mathrm{~km}^{2}$ and a population of 10 million. ${ }^{4}$ The central region includes the districts of Leiria, Coimbra, Viseu, Guarda, Castelo Branco and Aveirio and has a population of 1721650 inhabitants. $^{31}$

Patients residing outside the central region were included in the sample if the accident took place when they were in transit. This was done on the basis that this risk is identical to that suffered by Coimbra inhabitants outside their area of residence.

\section{Results}

In the central hospitals of Coimbra, research was done by informatized code, in accordance with the methodology outlined above; thus, the examination of clinical files identified led to the exclusion of: cases that did not present any neurological lesion; cases of spinal cord injury that were rehospitalized; vertebral lesions.

There has been a progressive increase in the number of SCI over the 4 years, with 68 new cases in 1989, 95 in 1990; 129 in 1991 and 106 in 1992.

From the clinical records of the HUC, only information relating to initial hospitalization was preserved, and $299(75.1 \%)$ files were identified and retained for statistical analysis.
At the $\mathrm{CHC}$, information relating to the initial hospitalization was preserved, and $95(23.8 \%)$ were identified and retained for statistical analysis, of which $89(22.4 \%)$ were from the General Hospital of the Coimbra Hospital Center (HG-CHC) and six (1.5\%) from the Coimbra Paediatric Hospital (HP-CHC).

At Coimbra IML, 2282 autopsy reports from between 1989 and 1992 were assessed, and 217 $(9.5 \%)$ which displayed evidence of SCI, were selected.

\section{Population}

From the files of the HUC, CHC and CIML, 398 cases of traumatic SCI were identified; $13(3.3 \%)$ were resident outside the stipulated region. There is a predominance of males: sex ratio 3.4-1. Distribution according to age shows a bimodal curve with two peaks (Figure 1): the first between 15 and 24 years, and the second (which is wider and has a greater amplitude) between 55 and 74 years; this explains the high average age of 50.53 years (standard deviation: 21.85).

With regards to marital status, 222 were married $(55.8 \%), 117$ single $(29.4 \%), 52$ were widowed $(13.1 \%)$ and seven divorced $(1.7 \%)$.

As far as the external cause of the lesion is concerned, there is a clear predominance of road accidents $(57.3 \%)$, followed by falls $(37.4 \%)$; other causes (such as aggression and other types of accident) formed a smaller group $(5.3 \%)$. This predominance of road accidents may be seen in almost all age-groups, except the 55-69 and 75-79 bands, in which falls predominate. Road accidents are predominant in the age bands $20-24(6.5 \%)$ and $70-74(6.8 \%)$; falls predominate in the group 55-69 $(5 \%)$.

With regards to the type of road accidents $(n=228)$, there is no significant difference between the number involving pedestrians and those involving two or fourwheeled vehicles. Analysis according to age-range shows that old people are more frequently run over (70-74 years and $80-84$ years: $5.3 \%$ for each), whilst younger people $(20-24$ years) are more frequently victims of accidents involving two-wheeled $(5.3 \%)$ or four-wheeled $(4.8 \%)$ vehicles.

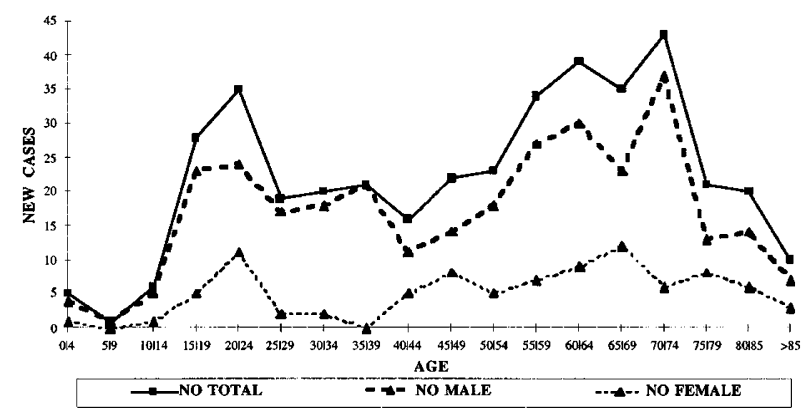

Figure 1 SCI new cases by age and sex, in the central region of Portugal (1989-1992) 
Children (5-14 years) and old people ( $70-90$ years) predominate amongst pedestrians. Accidents in twowheeled vehicles predominate in the $15-34$ and 50-64 age bands; accidents in 4-wheeled vehicles predominate between $20-24$ years and 35-49 years.

With regards to the treatment received after the accident, most $(53.8 \%)$ were taken to non-specialist hospitals, but were immediately transferred to a central hospital.

Four $(1 \%)$ were collected dead from the public highway by IML officials. For reasons of simplification, it has been decided that these will be included in the group 'dead on arrival at hospital'.

As far as the type of injury is concerned, there were 154 isolated SCI $(38.7 \%)$; in 120 cases $(30.1 \%)$ there were multiple associated injuries; in 66 cases $(16.6 \%)$ there was an associated traumatic brain injury; in 34 cases $(8.5 \%)$ there was an associated trauma of the thorax. In the hospitals concerned no Injury Severity Score (ISS) was carried out during hospitalization.

In $44.3 \%$ of cases, hospital treatment was restricted to verification of death or support of vital functions; due to the survival time and the initial state, it was not possible to initiate a specific treatment for SCI; for the rest, treatment consisted of surgery $(24.1 \%)$ and conservative orthopedic treatment $(31.6 \%)$, by skeletal traction in $4.8 \%$ of cases.

Of the 223 deaths resulting from road accidents or which took place during initial hospitalization, six were not subjected to autopsy for unknown reasons.

As regards the causes of neurological lesions, 183 fractures $(46 \%), 108$ luxation-fractures (27.1\%), 62 luxations $(15.6 \%), 17$ post-traumatic disc hernias $(4.3 \%), 10$ sub-luxations $(2.5 \%)$ and 18 without any distinct bone lesion (4.5\%). Osteo-articular lesion was found on the level of the cervical rachis in 204 cases $(51.2 \%)$, on the dorsal level in 163 cases $(41 \%)$ and on the lumbar level in 31 cases $(7.8 \%)$. Neurological lesion was complete in 220 cases $(55.6 \%)$ and incomplete in 176 cases $(44.4 \%)$.

\section{Incidence}

The annual incidence rate distributed according to age and sex per 100000 inhabitants is shown in Table 1; in all age groups, there is a predominance of males, with a peak in the $70-74$ age band.

In all new cases identified, the annual incidence rate is 57.8 per million inhabitants. Excluding victims who died on the way to hospital or in the first 30 days of hospitalization, the annual incidence rate is 25.4 per million inhabitants.

\section{Mortality}

Sixty-four $(16 \%)$ victims were declared dead on arrival at hospital. The coroner's autopsy identified SCI without physiopathological considerations: the description does not allow conclusions about the main cause of death. During hospitalization, 159 died (40\%), 16 during the third week $(7.2 \%)$ and three during the fourth week (1.4\%) (Figure 2). The number of deaths during the first $24 \mathrm{~h}$ was $100(44.9 \%)$, including the 64 declared dead on arrival. Thus, 210 individuals died during the first month, with another 13 deaths occurring during the following months; the average post-accident survival time was 35.4 days (standard deviation: 148.43).

Table 1 Frequency and annual incidence rate of spinal cord injury, by age and sex per 100000 inhabitants. Portugal's central region $1989-1992$

\begin{tabular}{|c|c|c|c|c|c|c|}
\hline \multirow[t]{2}{*}{ Age (years) } & \multicolumn{2}{|c|}{ Male } & \multicolumn{2}{|c|}{ Female } & \multicolumn{2}{|c|}{ Total } \\
\hline & No & Annual rate & No & Annual rate & No & Annual rate \\
\hline $0-4$ & 4 & 2.2 & 1 & 0.6 & 5 & 1.4 \\
\hline $5-9$ & 1 & 0.4 & 0 & 0.0 & 1 & 0.2 \\
\hline $10-14$ & 5 & 1.9 & 1 & 0.4 & 6 & 1.1 \\
\hline $15-19$ & 23 & 8.1 & 5 & 1.8 & 28 & 5.1 \\
\hline $20-24$ & 24 & 9.4 & 11 & 4.5 & 35 & 7.0 \\
\hline $25-29$ & 17 & 7.4 & 2 & 0.8 & 19 & 4.1 \\
\hline $30-34$ & 18 & 8.1 & 2 & 0.8 & 20 & 4.4 \\
\hline $35-39$ & 21 & 10.0 & 0 & 0.0 & 21 & 4.9 \\
\hline $40-44$ & 11 & 5.5 & 5 & 2.4 & 16 & 3.9 \\
\hline $45-49$ & 14 & 7.8 & 8 & 3.9 & 22 & 5.7 \\
\hline $50-54$ & 18 & 9.7 & 5 & 2.4 & 23 & 5.8 \\
\hline $55-59$ & 27 & 14.0 & 7 & 3.1 & 34 & 8.2 \\
\hline $60-64$ & 30 & 15.8 & 9 & 4.0 & 39 & 9.4 \\
\hline $65-69$ & 23 & 13.2 & 12 & 5.7 & 35 & 9.1 \\
\hline $70-74$ & 37 & 28.5 & 6 & 3.7 & 43 & 14.6 \\
\hline $75-79$ & 13 & 13.3 & 8 & 5.9 & 21 & 8.9 \\
\hline $80-84$ & 14 & 24.6 & 6 & 6.4 & 20 & 13.3 \\
\hline$\geqslant 85$ & 7 & 27.5 & 3 & 5.2 & 10 & 12.1 \\
\hline Total & 307 & 9.3 & 91 & 2.5 & 398 & 5.8 \\
\hline
\end{tabular}




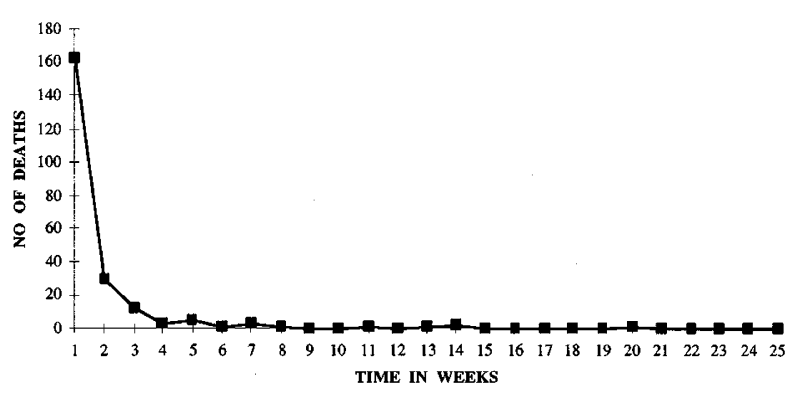

Figure 2 Mortality in SCI: prospective evolution in the central region of Portugal (1989-1992)

\section{Hospitalization}

The average length of hospitalization in the Coimbra central hospitals for 398 individuals was 26.67 days (standard deviation: 49.31), with a maximum of 539 days, making a total of 10615 days. Considering only individuals who arrived at hospital still alive (334), the average length of hospitalization was 31.78 days (standard deviation: 52.31 ). In $58.8 \%$ of cases, it was less than or equal to 15 days, and less than or equal to 30 days in $70.1 \%$ of cases.

On release from hospital, most of the 175 survivors $(29.8 \%)$ were transferred to a hospital nearer their residence and only 13 were sent directly to a rehabilitation center. Sixty-seven $(38.3 \%)$ were given follow-up consultations, of which 53 (30.3\%) were hospitalized in a rehabilitation center. The average waiting period for a consultation or hospitalization in a rehabilitation center was 201 days (standard deviation: 210.16), with a range of $32-1318$ days after the accident. The average hospitalization period was 112.9 days (standard deviation: 88.33) with an upper limit of 428 days; the hospitalization period was 4 months in $22 \%$ cases, 5 months in $11.8 \%$ and 6 months in $17.6 \%$ of cases.

\section{Discussion}

The annual incidence rate of SCI varies between seven and 54.8 new cases per million inhabitants. This variation is explained by the diversity in assessment methodology, by the inclusion or exclusion of individuals dead before arrival at hospital, by the date of the study, and also by the social and economic conditions of the country or region. However, few of these studies may be considered representative in epidemiological terms; amongst the publications which also consider cases of SCI that die during the initial phase, ${ }^{7,10,11,32}$ the annual incidence rate varies between 43 and 54.8. However, only Kraus $^{7}$ and Griffin ${ }^{11}$ also take into account individuals who die during the pre-hospitalization phase; in these cases the annual incidence rate varies between 53.4 and 54.8. In the central region of Portugal there was an annual incidence rate of 57.8 new cases per million inhabitants between 1989 and 1992, including the prehospital phase.
The average age of the population studied $(n=398)$ was 50.53 years; most publications present lower average ages, in the forties ${ }^{18,25}$ or even in the thirties. $7,10,14,16,20,26,33-35$ If we consider the number of cases per age band, there emerge two peaks of greater frequency, between 15 and 24 years and between 55 and 75 years. In this case, the reason for the contradiction with published studies is obvious: most of those authors ${ }^{16,21,34,36}$ claim that lesions predominate in the twenties age-band.

With regards to etiology, there is a clear predominance of road accidents $(57.3 \%)$ in most authors; ;,10,13,16-19,21,24-26,33-35 however, in Romania falls are the main cause of SCI. ${ }^{29}$

Like other authors, ${ }^{7,10,16,18,24-26,34}$ we found the second cause of SCI to be falls $(37.4 \%)$. These predominate above the age of 55 years, whilst in the United States they are more frequent above 65 years. ${ }^{37}$ Sport accidents, ${ }^{21}$ violence ${ }^{33,38}$ or work accidents ${ }^{19,29,39}$ are frequently cited as a second cause.

The route taken before arrival at a central hospital was responsible for lost time, and for unnecessary handling which aggravated the injury. This fact is reflected in the high number of cases (64) that were dead on arrival at one of the Coimbra hospital centers $(16 \%)$, and even for the high number of deaths in the first $24 \mathrm{~h}(100)$.

The level of bone lesion is divided roughly in half between the cervical level $(51.2 \%)$ and dorsal or lumbar level $(48.8 \%)$, as reported in recent publications, ${ }^{10,16,25,29,40-42}$ in contrast to older publications. ${ }^{19,34,39,43}$ However, most publications refer only to individuals still alive on admission to hospital.

\section{Conclusions}

Our study shows the real epidemiological scale of SCI in the central region of Portugal. In most countries of the world, SCI are nowadays a consequence of the 'highway war'. In Portugal, between 1989 and 1992, the number of traffic accidents increased by approximately $30 \%$, at both the national and the regional level. In the central region of Portugal, the number of cases of SCI increased by $55 \%$ between 1989 and 1992.

The risk of being a victim of SCI in the central region of Portugal may be expressed as 57.8 new cases per million inhabitants; the risk of dying in the initial phase of a medullary lesion is high, with a fatality of $56 \%$. This figure is a clear indication of the existing requirements at the level of collection, transportation, immediate medical and surgical care and rehabilitation during the acute phase. If only the survivors of the acute phase are taken into account, there are 25.4 new cases per year, per million inhabitants, which is an indication of the needs for rehabilitation and specific care of SCI cases in the central region of Portugal.

Thus, the epidemiological information collected makes a useful contribution to the planning of structures involved in rehabilitation. 


\section{References}

1 Kraus JF. A comparison of recent studies on the extent of the head and spinal cord injury problem in the United States. $J$ Neurosurg 1980; 53: S35-S43.

2 Yelnik A, Dizien O, Cordier C, Held JP. Épidémiologie des paraplégies traumatiques; quelques problèmes méthodologiques. In: Privat C, Hérisson C. Recontres autour du blessé médullaire. Paris, Masson. 1990; 192-196.

3 Dollfus P. Paraplégie: La situation de réadaption à l'heure européene. In: Privat C. Recontres autour du blessé médullaire. Paris: Masson, 1990: 197-202.

4 Anderson DW, Kalsbeek WD. The national head and spinal cord injury survey. Assessment of some uncertainties affecting the findings. J Neurosurg 1980; 53: S32-S34.

5 Kraus JF. Injury to head and spinal cord. The epidemiological relevance of the medical literature published from $1960-1978$. $J$ Neurosurg 1980; 53: S3-S10.

6 Diário da República. Ia Série, no 298, 29/12/87. Decreto-Lei no $387-\mathrm{C} / 87$.

7 Kraus JF, Franti CE, Riggins RS, et al. Incidence of traumatic spinal cord lesions. J Chronic Dis 1975; 28: 471-492.

8 Tolonen J, Santavirta S, Kiviluoto O, Lindqvist C. Fatal cervical spinal injuries in road traffic accidents. Injury 1986; 17: 154-158.

9 Martins F, Martins LA. Les lésions médullaires traumatiques: épidémiologie et rééducation dans la région centre du Portugal. In: Simon L, Pelissier J, Herisson Ch. Actualitiés en Rééducation Fonctionnelle et Réadaptation. Paris: Masson, 1990; 383-387.

10 Thurman DJ et al. Surveillance of spinal cord injuries in Utah, USA. Paraplegia 1994; 32: 665-669.

11 Griffin MR et al. Traumatic spinal cord injury in Olmsted county, Minnesota, 1935 - 1981. Am J Epidemiol 1985; 121: 884 895.

12 Acton PA et al. Traumatic spinal cord injury in Arkansas, 1980 1989. Arch Phys Med Rehabil 1993; 74: 1035-1040.

13 Biering-Sorenson F, Pederson V, Clausen S. Epidemiology of spinal cord lesions in Denmark. Paraplegia 1990; 28: 105-118.

14 Bracken MB. Incidence on traumatic hospitalized spinal cord injury in the United States 1970-77. Am J Epidemiol 1981; 113: $615-622$.

15 Burney RE, Maio RF, Maynard F, Karunas R. Incidence, characteristics, and outcome of spinal cord injury at trauma centers in North America. Arch Surg 1993; 128: 596-599.

16 Chen CF, Lien IN. Spinal cord injuries in Taipei, Taiwan. Paraplegia 1985; 23: $364-370$.

17 Fine PR, Kuhlemeier KV, De Vivo MJ, Stover SL. Spinal cord injury: an epidemiologic perspective. Paraplegia 1979-80; 17: $237-250$.

18 Garcia-Reneses J, Herruzo-Cabrera R, Martinez-Moreno M. Epidemiological study of spinal cord injury in Spain 1984-85. Paraplegia 1991; 28: $180-190$.

19 Gehrig R, Michaelis LS. Statistics of acute paraplegia and tetraplegia on a national scale (Switzerland 1960-67). Paraplegia 1986; 5: 93 - 95 .

20 Gjone R. Incidence of traumatic paraplegia and tetraplegia in Norway: a statistical survey of the years 1974-75. Paraplegia 1978-79; 16: $88-93$.

21 Griffiths ER. Spinal injury from swimming and diving treated in the spinal department of Royal Perth Rehabilitation Hospital: 1956-1978. Paraplegia 1980; 18: 100-117.

22 Harlid R, Andersson G. The Swedish experience in the organisation of domiciliary ventilation for patients with a high spinal cord injury. Paraplegia 1993; 31: 157-159.
23 Karamehmetoglu SS, et al. Traumatic spinal cord injuries in Istanbul, Turkey. An epidemiological study. Paraplegia 1995; 33: $469-471$.

24 Knútsdóttir S. Spinal cord injuries in Iceland 1973-1989. A follow up study. Paraplegia 1993; 31: $68-72$.

25 Lan C et al. Traumatic spinal cord injuries in the rural region of Taiwan: an epidemiological study in Hualien county, 19861990. Paraplegia 1993; 31: 398 - 403.

26 Minaire $\mathrm{P}$ et al. Epidemiology of spinal cord injury in the RhôneAlpes region, France, 1970-1975. Paraplegia 1978-79; 16: 76 87.

27 Silberstein B, Rabinovich S. Epidemiology of spinal cord injuries in Novosibirsk, Russia. Paraplegia 1995; 33: $322-325$.

28 Shingu H, Ikata T, Katoh S, Akatsu T. Spinal cord injuries in Japan: a nationwide epidemiological survey in 1990. Paraplegia 1994; 32: $3-8$.

29 Soopramanien A. Epidemiology of spinal injuries in Romania. Paraplegia 1994; 32: $715-722$.

30 Ditunno JF, Young W, Donovan WH, Cresey G. The International Standards Booklet for neurological and functional classification of spinal cord injury. Paraplegia 1994; 32: $70-80$.

31 Instituto Nacional de Estatística. Censos 91 - Resultados definitivos - Centro. Instituto Nacional de Estatistica. Lisboa 1993, $2^{\circ}$ vol.

32 Price C, Makintubee S, Herdnon W, Istre GR. Epidemiology of traumatic spinal cord injury and acute hospitalization and rehabilitation charges for spinal cord injuries in Oklahokma, 1988-90. Am J Epidemiol 1994; 139: 37-47.

33 Campos da Paz A, et al. Traumatic injury to the spinal cord. Prevalence in Brazilian hospitals. Paraplegia 1992; 30: 636-640.

34 Dineer F, et al. Traumatic spinal cord injuries in Turkey. Paraplegia 1992; 30: $641-646$.

35 Yarkony GM, et al. Spinal cord injury care system: fifteen year experience at the Rehabilitation Institute of Chicago. Paraplegia 1990; 28: $321-329$

36 Masini M, Neto NGF, Neves EGC. Experience with a spinal cord unit in Brasilia, Brazil. Paraplegia 1990; 28: 17-24.

37 MMWR. Trends in traumatic spinal cord injury - New York, 1982-1988. MMWR 1991; 31: 535-543.

38 Hart C, Williams E. Epidemiology of spinal cord injuries: a reflection of changes in South African society. Paraplegia 1994; 32: $709-714$.

39 Gaspar VG, Maia Silva R. Spinal cord lesions due to water sports and occupations: our experience in 20 years. Paraplegia 1980; 18: $106-108$.

40 Daverat P, Barat M. Pronostic fonctionnel précoce des traumatismes médullaires. In: Privat C, Herisson C.Rencontres autour du blessé médullaire. Paris: Masson, 1990; 135-141.

41 Daverat $\mathrm{P}$, et al. Initial factors predicting survival in patients with a spinal cord injury. J Neurol Neurosurg Psychiatry 1989; 52: $403-406$.

42 Daverat $\mathrm{P}$, et al. Valeur prédictive de l'examen neurologique initial sur la récupération de la marche chez le blessé médullaire. Ann Readaptation Med Phy 1987; 30: 369-379.

43 Silver JR, Gibbon NOK. Prognosis in tetraplegia. Br Med J 1968; 4: $79-83$. 